\title{
O método das vogais cardeais e as vogais do português brasileiro ${ }^{1}$
}

\author{
Thaïs Cristófaro Silva \\ Universidade Federal de Minas Gerais \\ Kings College London
}

\section{Abstract}

This paper presents an analysis of the vocalic system of Brazilian Portuguese based on the method of Cardinal Vowels (Abercrombie (1967), Jones (1980)). First we present a basic description of the principles of the method of Cardinal Vowels since such a technique is not available in Portuguese. Following the theoretical description we present the application of the method to describe the oral vowel system of Brazilian Portuguese. Finally, we suggest some topics for further research. 


\section{INTRODUÇÃO}

$\mathrm{E}$

ste artigo apresenta uma proposta de análise do sistema vocálico do português brasileiro baseada no Método das Vogais cardeais (ABERCROMBIE (1967), JONES (1980)). Inicialmente descrevemos em detalhes tal método. Tal descrição justifica-se em primeiro lugar por não contarmos com a publicação de tal método e seus princípios básicos em livros ou periódicos publicados em língua portuguesa. Em segundo lugar o método das Vogais cardeais continua, ainda hoje, sendo o recurso mais adequado para a descrição dos segmentos vocálicos que ocorrem nas línguas naturais. Após a apresentação do método discute-se a aplicação de tal técnica na análise do sistema vocálico oral do português brasileiro. A partir da proposta apresentada sugerem-se alguns aspectos a serem investigados em pesquisas futuras.

\section{O MÉTODO DAS VOGAIS CARDEAIS}

O método das Vogais cardeais propõe um sistema descritivo e classificatório para os segmentos vocálicos. Adotam-se pontos de referência para descrever as vogais. A idéia de adotar-se um sistema de pontos de referência para a classificação de vogais foi inicialmente proposta por A. J. Ellis em 1844 (apud ABERCROMBIE (1967:151)). O termo "cardeal", em analogia ao sistema de pontos geográficos, foi usado por Bell em 1867. No início do século Daniel Jones apresentou o método das Vogais cardeais. Na primeira edição do English pronouncing dictionary, em 1917, Daniel Jones classifica as vogais do inglês a partir de tal método. Este recurso descritivo foi desenvolvido ao ponto em que se encontra hoje por ABERCROMBIE 
(1967). O Alfabeto Internacional de Fonética classifica as vogais de acordo com tal método (IPA (1982, 1996)). LADEFOGED \& MADDIESON (1996) oferecem uma excelente discussão dos princípios de caracterização dos segmentos vocálicos em várias línguas. O método das Vogais cardeais permite-nos caracterizar qualquer segmento vocálico de qualquer língua. ${ }^{2}$

Vejamos então os princípios básicos deste método com o objetivo de identificarmos qualquer segmento vocálico passível de ser articulado. De acordo com esta proposta uma vogal cardeal - que abreviaremos por VC - é definida como:

“... um ponto de referência fixo e imutável estabelecido dentro do limite da área vocálica, ao qual qualquer outro som vocálico pode ser relacionado diretamente. Um conjunto destes pontos de referência constitui um sistema de vogais cardeais e qualquer vogal em qualquer língua pode ser 'identificada' neste sistema.' (ABERCROMBIE (1967:151).

De acordo com a definição acima, podemos dizer que qualquer vogal pode ser descrita como sendo associada a um ponto de referência específico dentro da área vocálica. As vogais cardeais são de qualidade invariável e exatamente determinadas. A descrição de vogais específicas de uma língua tomará como referência os pontos correspondentes às vogais cardeais. Por definição as vogais cardeais são auditivamente eqüidistantes, sendo localizadas no limite da área vocálica.

Algumas línguas podem apresentar várias de suas vogais em uma posição idêntica ou bem próxima às vogais cardeais. Pode ser também que nenhuma das vogais de uma determinada língua seja produzida próximo a qualquer uma das vogais cardeais.

Os pontos mais importantes do sistema de vogais cardeais podem ser resumidos nos seguintes itens (cf. ABERCROMBIE (1967:154)):

- As VC são selecionadas arbitrariamente; uma VC é um recurso descritivo e não algo que ocorra necessariamente em alguma língua. 
- As VC são de qualidade invariável e exatamente determinadas.

- As VC são vogais periféricas: o ponto mais alto da língua para cada uma delas ocorre nos limites extremos da área vocálica (ou seja, a linha periférica).

- As VC são auditivamente eqüidistantes.

- As VC são em número de oito.

O método das Vogais cardeais propõe um recurso de descrição das vogais a partir de parâmetros auditivos que caracterizam uma vogal dentro da área vocálica. A área vocálica compreende parte da cavidade bucal onde a língua assume diferentes posições na articulação das vogais sem causar fricção ou obstrução. A área vocálica é delimitada pela linha periférica. Para definirmos a área limítrofe da área vocálica - ou linha periférica - devemos identificar em que posição articulatória a nossa língua gera a ocorrência de fricção devido à passagem da corrente de ar pela cavidade bucal. Tal fricção é audível e a posição da língua neste local define a linha periférica e indica o ponto de transição entre segmentos consonantais e vocálicos. Quando a friç̧ão ocorre dá-se início a uma articulação consonantal. As vogais são caracterizadas pela não-fricção ou obstrução da passagem da corrente de ar e são articuladas na parte da cavidade bucal que precede a ocorrência da fricção. Toda e qualquer pessoa pode definir a linha periférica da área vocálica em seu trato vocal. Assim, será definida a área limítrofe de produção de segmentos consonantais e vocálicos. Tentemos primeiro definir o ponto da linha periférica que se localiza na parte mais à frente e mais alta da cavidade bucal.

Considere, por exemplo, a vogal $i$ como na palavra saci e lentamente altere a posição de sua língua para uma posição mais alta e mais à frente (ou anterior) possível. Observe que em um determinado momento o levantamento do corpo da língua para uma posição mais elevada e ao mesmo tempo mais para frente provoca uma fricção audível. A ocorrência da fricção caracteriza um segmento consonantal. Este é portanto o segmento fricativo [j] que corresponde 
ao som inicial da palavra ['jes] 'yes' do inglês e não ocorre em português.

A área limítrofe entre a ocorrência ou não da frição define a área vocálica que é delimitada pela linha periférica. Segmentos produzidos antes da ocorrência da fricção são vocálicos e segmentos produzidos após o início da fricção são consonantais. O procedimento adotado acima nos levou a definir o ponto da linha periférica para a posição mais avançada e mais alta na cavidade bucal tomando-se como referência a vogal $i$. Tal ponto refere-se à "Vogal cardeal No. 1", ou seja, VC1. O mesmo procedimento pode ser adotado para definirmos outros pontos na linha periférica. Consideremos por exemplo a articulação do ponto mais baixo e mais posterior possível sem que haja fricção audivel. Deve-se articular uma vogal com a língua na posição mais baixa possível e ao mesmo tempo deve-se recuar a língua para a posição mais posterior possível. O ponto em que se ouve a fricção audível delimita a área vocálica. O segmento consonantal nesta posição limítrofe é [в] que corresponde à fricativa uvular vozeada (tal segmento não ocorre em português). O ponto que precede o início da fricção refere-se ao ponto mais baixo e recuado possível que corresponde a VC5, cujo símbolo é [a]. Tal vogal não ocorre em português. Como referência articulatória para falantes do português identificarem a VC5 sugiro que se articule a vogal [o] como na palavra só e gradualmente abaixe e recue a língua o máximo possível até ao ponto que precede o início da fricção. ABERCROMBIE (1967:157) sugere um diagrama com formato oval para caracterizar a área vocálica. Em tal diagrama a parte mais alta e mais à frente da cavidade bucal é indicada por (VC1) e a parte mais posterior e mais baixa da cavidade bucal é indicada por (VC5). Daniel Jones propôs alterar a representação da área vocálica com formato oval e propõe uma figura com linhas retas e com forma geométrica (cf. JONES, 1980:36). Ilustramos a seguir a localização da área vocálica na cavidade bucal com a representação oval e em forma de trapézio. A figura da esquerda aponta a representação oval sugerida por ABERCROMBIE (1967:157)). A 
figura da direita indica a representação em forma de trapézio. A proposta de JONES (1980) de representação da área vocálica em forma de trapézio passa a predominar na literatura.

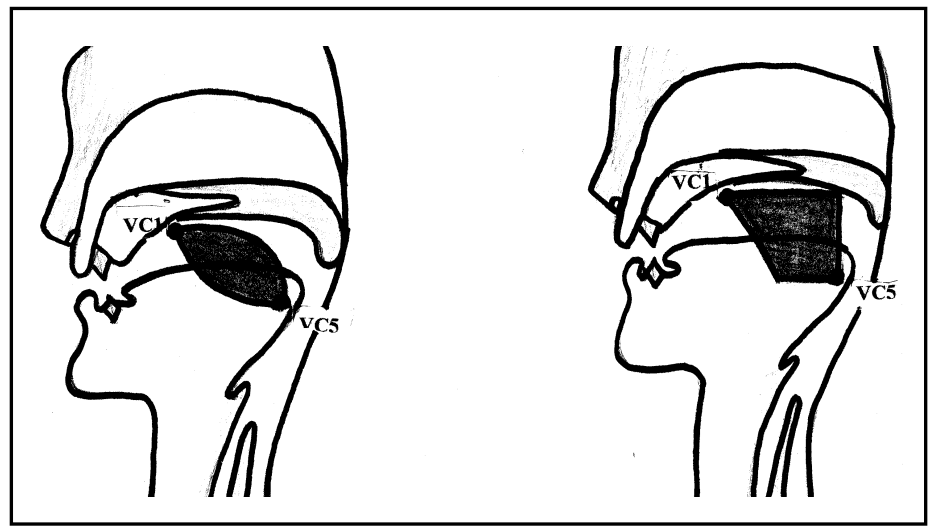

FIGURA 1 - Figuras identificando a área vocálica no aparelho fonador

Consideremos em detalhes a representação da área vocálica em forma de trapézio. No diagrama abaixo ilustra-se tal diagrama em que as vogais cardeais primárias VC1 a VC8 são identificadas (compare esta figura com a figura 1).

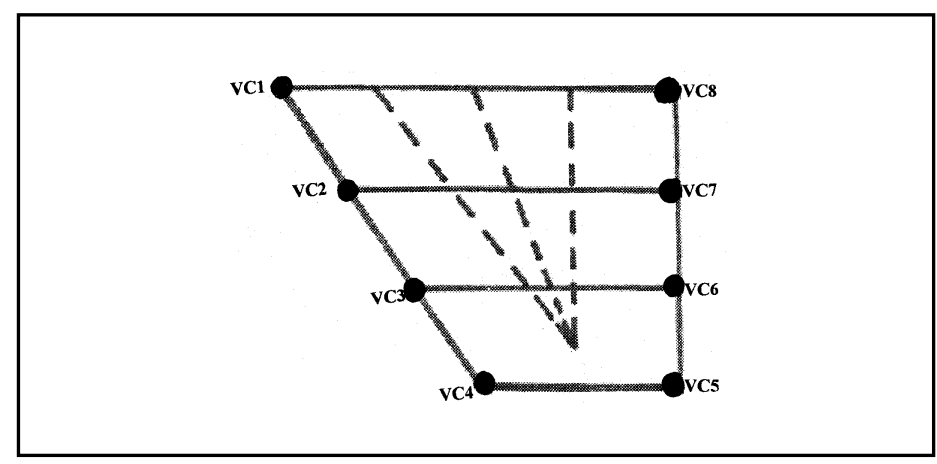

FIGURA 2 - Diagrama do trapézio correspondente à área vocálica, ilustrando os pontos referenciais das vogais cardeais primárias 
O ponto VC1 corresponde à vogal [i] e o ponto VC5 corresponde à vogal [a]. Estes segmentos já foram identificados anteriormente. Resta-nos caracterizar os demais pontos de referência que se relacionam às vogais cardeais restantes. Em direção descendente entre VC1 e VC5 identificamos três pontos eqüidistantes auditivamente. Estes três pontos correspondem respectivamente às vogais cardeais VC2, VC3, VC4. Outros três pontos eqüidistantes auditivamente devem ser identificados em direção ascendente entre VC5 e VC1. Estes pontos correspondem respectivamente às vogais cardeais VC6, VC7, VC8. As oito vogais cardeais identificadas representam as vogais cardeais primárias cujos símbolos correspondentes são:

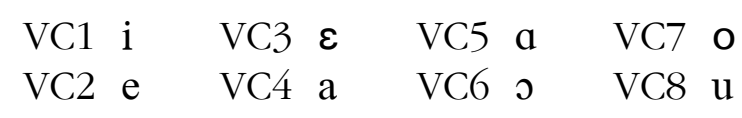

O procedimento apresentado acima para classificar as vogais cardeais primárias nos permite definir todos os pontos da linha periférica e caracterizarmos nossa área vocálica. Este contorno da linha periférica da área vocálica pode ser observado ao pronunciarmos em seqüência as vogais cardeais primárias listadas acima: [i, e, $\varepsilon, a, a, o, o, u]$. Uma articulação produzida na linha periférica ou na área interior delimitada por esta linha periférica será um segmento vocálico. Segmentos que são produzidos fora da linha periférica correspondem a segmentos consonantais.

Encontra-se à venda uma gravação dos sons adotados pelo Alfabeto Internacional de Fonética (bttp://www2.arts.gla.ac.uk/IPA). Dentre estes sons temos a gravação das Vogais Cardeais (e obviamente das consoantes também). Este material, elaborado pelo Professor John Wells do University College London, pode ser obtido em fita cassete (U\$12) ou em CD (U\$17) (http://www.phon.ucl. ac.uk/home/wells/cassette.htm).

JONES (1980) argumenta que as vogais cardeais periféricas oferecem o ponto de referência mais adequado para a descrição de qualquer segmento vocálico. O trapézio que utilizamos para 
representar as VC é construído com as seguintes dimensões: base de 2 unidades, linha vertical à direita de 3 unidades e linha superior de 4 unidades (estas unidades podem ser centímetros por exemplo). No diagrama da figura 2 assumimos que cada unidade mede $1 \mathrm{~cm}$. Portanto o trapézio da figura 2 tem as seguintes medidas: base $2 \mathrm{~cm}$; linha vertical à direita de $3 \mathrm{~cm}$ e linha superior de $4 \mathrm{~cm}$. Fecha-se $\mathrm{o}$ trapézio ligando a linha superior do diagrama à base ou linha inferior. O perímetro do trapézio corresponde à linha periférica, que, juntamente com a região interna do trapézio, define a área vocálica. As vogais cardeais primárias VC1 a VC8 são indicadas na FIG. 3 pelos oito pontos eqüidistantes situados na linha externa do trapézio. As VC1 a VC5 não são labializadas - ou seja, não apresentam arredondamento dos lábios - enquanto que as VC6 a VC8 são labializadas, apresentando portanto arredondamento dos lábios.

Consideremos agora as linhas pontilhadas internas no diagrama da FIG. 2. Estas linhas delimitam a parte central da área vocálica. Identifique o ponto médio da linha superior (entre VC1 e VC8). Para isto pronuncie continuamente as VC1 e VC8: $i$ e $u$. Tal ponto deve corresponder a uma vogal central articulada na parte superior da área vocálica. Em seguida identifique o ponto médio entre VC4 e VC5. O ponto médio entre VC1 e VC8 deve ser ligado por uma linha pontilhada ao ponto médio próximo à linha inferior entre VC4 e VC5. Esta linha não deve tocar a linha inferior entre VC4 e VC5. Trace em seguida uma linha pontilhada que seja paralela à linha da direita onde localizam-se VC5 a VC8. Finalmente trace uma linha pontilhada que seja paralela à linha da esquerda onde localizam-se VC1 a VC4. Completamos assim a descrição geométrica do diagrama do trapézio correspondente à área vocálica que foi apresentada na FIG. 2.

As propostas de ABERCROMBIE (1967) e JONES (1980) permitem a identificação dos parâmetros articulatórios de altura (alto $\leftrightarrow$ baixo) e de posição da língua (anterior $\leftrightarrow$ posterior) conforme ilustrado na FIG. 2, LADEFOGED \& MADDIESON (1996:283) sugerem que o diagrama das Vogais cardeais incorpore o parâmetro articulatório referente à posição dos lábios (arredondado $\leftrightarrow$ não-arredondado). 
Expressamos esta proposta na representação tridimensional das Vogais Cardeais apresentada abaixo (cf. LADEFOGED \& MADDIESON, 1996:285).

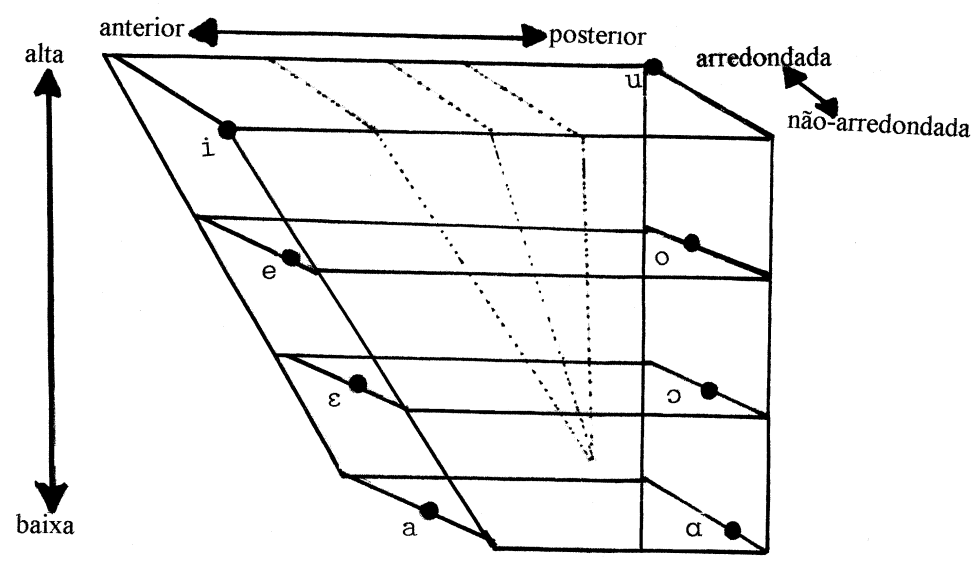

FIGURA 3 - As vogais cardeais primárias expressas em termos das principais características articulatórias: (alto $\leftrightarrow$ baixo); (anterior $\leftrightarrow$ posterior) e (arredondado $\leftrightarrow$ não-arredondado)

LADEFOGED \& MADDIESON (1996) argumentam que a identificação de segmentos vocálicos em um quadro baseado em parâmetros auditivos - como o diagrama em forma de trapézio apresentado na FIG. 2 - encontra apoio teórico mais em parâmetros acústicos do que em parâmetros articulatórios. Contudo, parâmetros articulatórios não devem ser ignorados na descrição fonética dos segmentos vocálicos (cf. LADEFOGED \& MADDIESON, 1996:285). O diagrama tridimensional (ver FIG. 3) permite expressar os três parâmetros articulatórios básicos utilizados na descrição das vogais: (alto $\leftrightarrow$ baixo); (anterior $\leftrightarrow$ posterior) e (arredondado $\leftrightarrow$ nãoarredondado). 
Temos vogais cardeais primárias (cf. FIG. 2) e vogais cardeais secundárias. As vogais cardeais primárias são em número de oito e temos quatorze vogais cardeais secundárias. As VC secundárias são representadas pelos pontos VC9 a VC22 conforme ilustrado no diagrama abaixo.

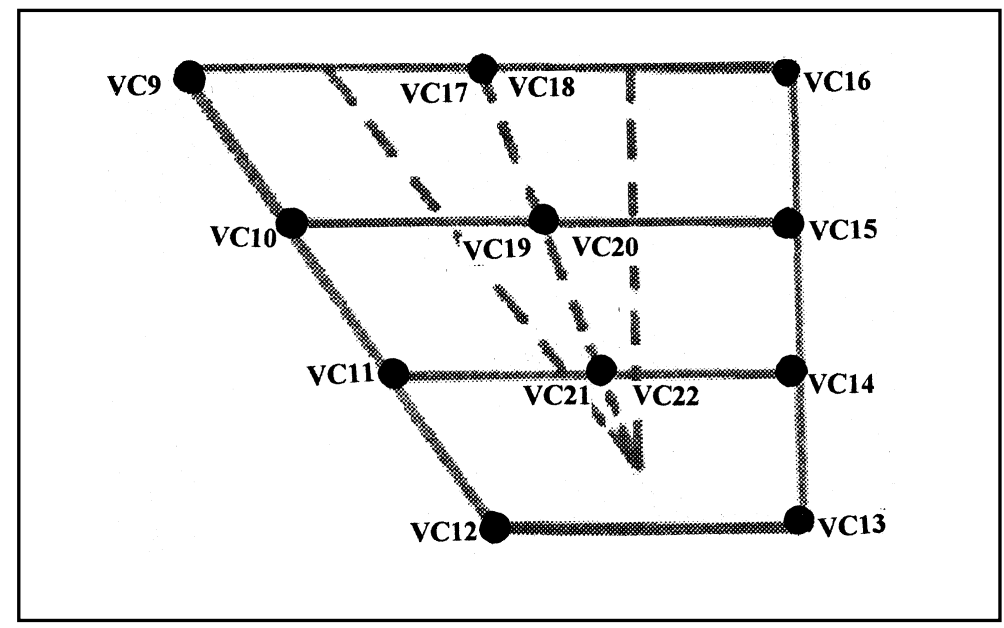

FIGURA 4 - Diagrama do trapézio correspondente à área vocálica ilustrando os pontos referenciais das vogais cardeais secundárias

As VC secundárias VC9 a VC18 são localizadas na linha periférica e as VC19 a VC22 são centrais. As VC9 a VC16 são determinadas a partir da mesma posição da língua assumida para as VC1 a VC8. Entretanto, elas caracterizam-se pela inversão da postura dos lábios em relação às VC primárias. Em outras palavras, as VC9 a VC16 correspondem às posições das VC primárias representadas na linha periférica do diagrama ilustrado na FIG. 3, exceto pela posição dos lábios. As VC9 a VC13 são labializadas e VC14 a VC16 não são labializadas. Estas $V C$ secundárias periféricas são representadas pelos seguintes símbolos: 


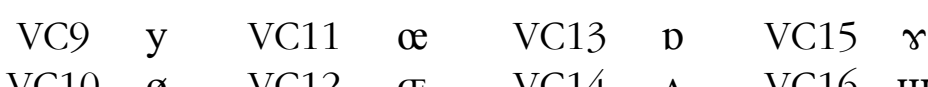

Pode-se identificar as VC9-VC16 em relação às VC primárias VC1-VC8 com a inversão da posição dos lábios. Lembre-se de que nas vogais cardeais primárias VC1-VC8 temos que as vogais primárias anteriores VC1-VC4 [i, e, $\varepsilon$, a] são produzidas sem o arredondamento dos lábios, ou seja, os lábios devem estar distendidos. Já para as vogais secundárias anteriores VC9-VC12 [y, ø, œ, ๓], observa-se o arredondamento dos lábios. Somente a posição dos lábios distingue as vogais secundárias anteriores VC9-VC12 [y, ø, œ, ๓] (que são arredondadas) das vogais primárias anteriores VC1-VC4 [i, e, $\varepsilon$, a] (que são não-arredondadas). De maneira análoga as vogais secundárias posteriores VC13-16 [p, $\Lambda, \gamma$, u] devem ser articuladas da mesma maneira que as vogais primárias posteriores VC5-VC8 [a, o, o, u] diferindo-se também apenas quanto ao arredondamento dos lábios. As vogais primárias posteriores VC5-VC8 [a, o, o, u] são produzidas com o arredondamento dos lábios e as vogais primárias posteriores VC13-VC16 [p, $\Lambda, \gamma$, u] são produzidas com os lábios distendidos.

Consideremos agora as vogais cardeais secundárias restantes, ou seja VC17 a VC22. Estas vogais localizam-se na parte central da área vocálica. O ponto médio construído a partir dos pontos de referência VC9 e VC16 determina as duas VC secundárias e periféricas que são representadas pelos pontos VC17: [i]] (sem labialização) e VC18: [u] (com labialização). Note que os pontos VC17 e VC18 encontram-se na linha periférica que tem interseção com a linha central pontilhada do diagrama. Nesta linha central pontilhada temos outros dois pontos localizados no interior da área vocálica, que correspondem aos pontos médios construídos a partir dos pontos de referência VC10 e VC15 e dos pontos de referência VC11 e VC14. O ponto médio entre VC10 e VC15 representa as VC19: [э] (sem labialização) e VC20: [ө] (com labialização). O ponto médio entre VC11 e VC14 representa as VC21: [3] (sem labialização) e VC22: [в] 
(com labialização). Estas demais VC secundárias centrais são representadas pelos seguintes símbolos:

\begin{tabular}{|c|c|c|c|c|}
\hline VC17 & $\dot{\mathrm{i}}$ & VC19 & э & VC21 \\
\hline VC18 & u & VC20 & $\theta$ & VC22 \\
\hline
\end{tabular}

Tomando como referência os valores cardeais descritos acima, podemos identificar qualquer segmento vocálico de qualquer língua. Podemos adotar um dos símbolos apresentados para a vogal cardeal mais próxima à vogal que pretendemos descrever ou podemos utilizar um dos diacríticos abaixo para precisar a localização de tal vogal na área vocálica.

$\begin{array}{lll}+ & \text { levantada } & \text { qualidade mais alta } \\ + & \text { abaixada } & \text { qualidade mais baixa } \\ + & \text { retraída } & \text { qualidade mais posterior } \\ + & \text { avançada } & \text { qualidade mais anterior }\end{array}$

A presença de um destes diacríticos indicará a alteração da qualidade da vogal que estamos descrevendo em relação a uma vogal cardeal tomada como referência. Os diacríticos são colocados abaixo dos símbolos fonéticos utilizados para caracterizar um segmento vocálico. Por exemplo, um símbolo como [ị] indica que tomamos como referência a VC1: [i] com uma qualidade vocálica mais baixa. Se quisermos indicar que a vogal que estamos descrevendo é mais retraída e também mais baixa devemos colocar os diacríticos , e , abaixo do símbolo da VC que tomamos como referência. Geralmente os lingüistas adotam os símbolos propostos para as VCs em suas descrições. Este recurso permite a caracterização de segmentos vocálicos que ocorram em certa região específica da área vocálica com símbolos semelhantes. Contudo, uma descrição completa de qualquer segmento vocálico deve explicitar todas as características auditivas, articulatórias e acústicas envolvidas na análise. Procedemos a seguir à descrição das propriedades articulatórias ou articulações secundárias das vogais que contribuem para uma descrição mais precisa dos segmentos vocálicos. 
Apresentamos a seguir o diagrama das Vogais cardeais que reproduzimos do quadro da Associação Internacional de Fonética. ${ }^{3}$

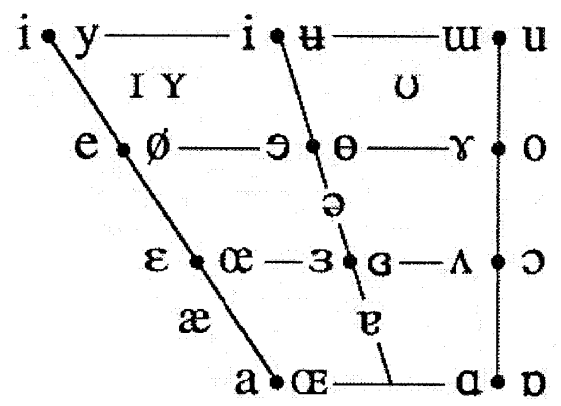

FIGURA 5 - Diagrama das Vogais cardeais - Associação Internacional de Fonética

\section{ARTICULAÇÕES SECUNDÁRIAS DOS SEGMENTOS VOCÁLICOS}

Discutimos abaixo algumas das propriedades articulatórias secundárias observadas durante a produção de segmentos vocálicos. Tomamos como referência, para a descrição apresentada a seguir, os trabalhos de ABERCROMBIE (1967) e CAGLIARI (1981).

\subsection{Duração}

A duração de um determinado segmento só pode ser medida comparativamente em relação a outros segmentos. Em outras palavras, a duração é uma medida relativa entre segmentos. Os diacríticos abaixo são utilizados para marcar a duração dos segmentos vocálicos. Todos os exemplos são ilustrados com a vogal $a$, mas os diacríticos podem acompanhar qualquer segmento vocálico.

a: duração longa

a' duração média

ă duração extra breve 
Se em uma determinada língua a duração não se faz relevante, o símbolo utilizado sem nenhum diacrítico corresponderá às vogais daquela língua, por exemplo: [a]. Isto porque a duração é obrigatóriamente comparativa. Outros fatores, como o acento tônico, por exemplo, influenciam na duração de uma vogal. Assim, vogais acentuadas tendem a ser mais longas. Se este for o caso na língua a ser descrita, pode-se assumir que a duração é causada pelo acento e não em oposição a outras vogais do sistema daquela língua. Em algumas línguas a duração é extremamente importante na produção dos segmentos vocálicos, como o inglês por exemplo. Em português este não é o caso.

\subsection{Desvozeamento}

Normalmente, segmentos vocálicos são vozeados, isto é, durante a sua produção as cordas vocais estão vibrando. Contudo, segmentos vocálicos podem ser produzidos com a propriedade articulatória secundária de desvozeamento. Neste caso, as cordas vocais não vibram durante a produção da vogal (de maneira análoga a consoantes desvozeadas). Faremos uso de um pequeno círculo colocado abaixo do segmento vocálico para caracterizar a propriedade secundária de desvozeamento. Assim, [a¥] caracteriza o segmento [a] com a propriedade de desvozeamento. Em português o desvozeamento de segmentos vocálicos geralmente ocorre em vogais não-acentuadas em final de palavra, como por exemplo as vogais finais das palavras pata, sapo, bote.

\subsection{Nasalização}

Se durante a articulação de uma vogal ocorrer o abaixamento do véu palatino, parte do fluxo de ar penetrará na cavidade nasal sendo expelido pelas narinas e produzindo assim uma qualidade vocálica nasalizada. Faremos uso de um til, i.e. , colocado acima do segmento vocálico para marcar a nasalidade. Assim, [ã] caracteriza o segmento [a] com a propriedade de nasalização. 


\section{SOBRE A CLASSIFICAÇÃO DOS SEGMENTOS VOCÁLICOS}

Embora o método das Vogais cardeais forneça um recurso descritivo bastante preciso para a caracterização de sistemas vocálicos, é bastante comum encontrarmos na literatura o agrupamento das vogais em relação às seguintes características: a) arredondamento ou não dos lábios; b) anterioridade ou posterioridade da posição da língua (que também pode ser central) e c) altura da língua, que pode ser dividida entre três ou quatro grupos dependendo do sistema vocálico em questão. Conforme vimos anteriormente na FIG. 3, um trapézio tridimensional pode expressar as características articulatórias que são freqüentemente adotadas na descrição dos segmentos vocálicos: (alto $\leftrightarrow$ baixo); (anterior $\leftrightarrow$ posterior) e (arredondado $\leftrightarrow$ não-arredondado). Abaixo apresentamos um quadro fazendo uso dos símbolos adotados para a transcrição das vogais cardeais que caracteriza as vogais quanto aos três parâmetros articulatórios apontados anteriormente. Na primeira linha indica-se a posição da língua quanto à (anterioridade $\leftrightarrow$ posterioridade) - ou a vogal pode ser central - e indica-se também a posição assumida pelos lábios: (arredondados $\leftrightarrow$ não-arredondados). Na coluna da esquerda indica-se a altura que é expressa em quatro graus: alta; média alta; média-baixa; baixa. Em sistemas vocálicos em que apenas três graus de altura são relevantes temos as seguintes categorias para a altura da língua: alta, média e baixa.

\section{QUADRO 1}

Classificação das vogais quanto ao arredondamento dos lábios, anterioridade/posterioridade e altura

\begin{tabular}{|c|c|c|c|c|c|c|}
\hline & \multicolumn{2}{|c|}{ anterior } & \multicolumn{2}{|c|}{ central } & \multicolumn{2}{|c|}{ posterior } \\
\hline & arred. & não-arred. & arred. & não-arred. & arred. & não-arred. \\
\hline alta & $\mathrm{y}$ & $i$ & $\dot{\dot{x}}$ & $H$ & $\mathrm{u}$ & u \\
\hline média-alta & $\varnothing$ & e & $\ominus$ & $\theta$ & o & $\gamma$ \\
\hline média-baixa & $œ$ & $\varepsilon$ & 3 & B & o & $\Lambda$ \\
\hline baixa & $\mathbb{E}$ & $\mathrm{a}$ & & e & $\mathrm{p}$ & $a$ \\
\hline
\end{tabular}


Do ponto de vista de nomeclatura as vogais são categorizadas quanto a três parâmetros na seguinte ordem:

altura

corpo da língua

arredondamento alta, média-alta, baixa, média-baixa

anterior, central, posterior

arredondada, não-arredondada

Assim, a classificação da vogal [i] é: "vogal alta anterior nãoarredondada". Propriedades articulatórias secundárias - como duração, vozeamento e nasalização - são indicadas como último item na classificação. Assim, um segmento como [ĩ] é classificado como "vogal alta anterior não-arredondada nasalizada". Vejamos finalmente um método de descrição de ditongos.

\section{A DESCRIÇÃO DOS DITONGOS}

Ditongos são comumente tratados como uma seqüência de segmentos. Um dos segmentos da seqüência é interpretado como uma vogal e o outro é interpretado como semivocóide, semicontóide, semivogal, vogal assilábica ou glide. Faremos uso do termo glide (pronuncia-se 'gl[ai]de') em detrimento destes outros termos. A descrição que se segue é baseada no sistema das Vogais cardeais discutido anteriormente.

Do ponto de vista fonético o que caracteriza um segmento como vocálico ou consonantalé o fato de haver ou não obstrução da passagem da corrente de ar pelo trato vocal. Segmentos vocálicos apresentam a passagem livre da corrente de ar. Segmentos consonantais apresentam obstrução ou fricção. Um ditongo é uma vogal que apresenta mudanças de qualidade continuamente dentro de um percurso na área vocálica. As vogais que não apresentam mudança de qualidade são chamadas monotongos e foram descritas anteriormente. Um ditongo pode ser descrito e identificado com referência aos valores das vogais cardeais. Representamos um ditongo por uma seta no diagrama da área vocálica. A seta começa na vogal cardeal em que o ditongo se inicia e termina na vogal cardeal em que o 
ditongo é concluído. Assim, para representarmos o ditongo ai da palavra pais traçamos uma linha na área vocálica que se inicia na área referente à vogal [a] e termina na área referente à vogal [i]. Do ponto de vista articulatório expressamos que ocorre um movimento contínuo e gradual da língua entre duas posições articulatórias. Tal articulação ocupa uma única sílaba. O diagrama abaixo ilustra os ditongos que ocorrem nas palavras pais e pau ${ }^{4}$

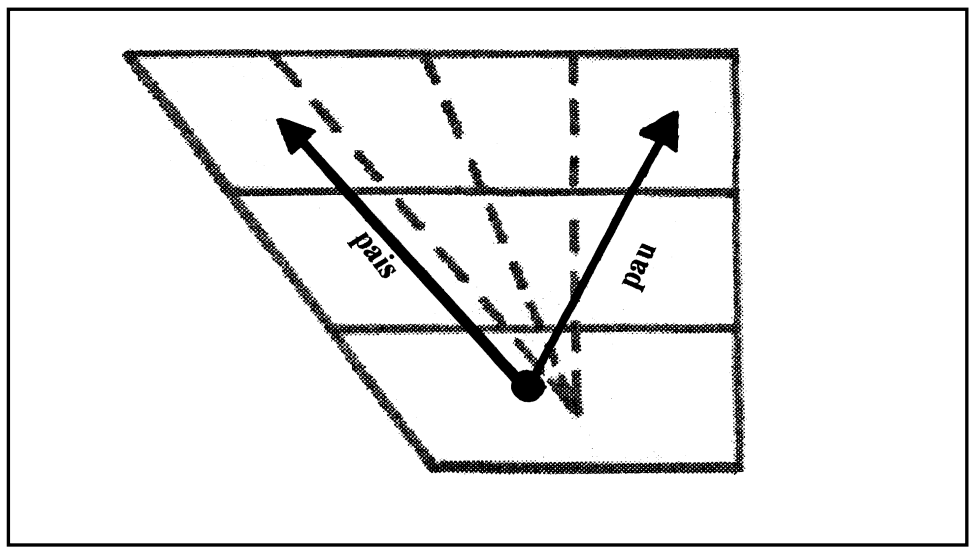

FIGURA 6 - Os ditongo nas palavras pais e pau

O movimento articulatório de um ditongo difere do movimento articulatório de duas vogais em seqüência sobretudo quanto ao tempo ocupado na estrutura silábica e quanto à mudança de qualidade vocálica. O par de palavras pais e país ilustra um ditongo - na primeira palavra - em oposição a uma seqüência de vogais - na segunda palavra. Durante a articulação de duas vogais em seqüência - como na palavra país - cada vogal ocorre em uma sílaba distinta e cada vogal apresenta qualidade vocálica específica. Já em ditongos - como na palavra pais - as duas vogais ocorrem na mesma sílaba e há uma mudança contínua e gradual entre as vogais em questão. Portanto, um ditongo distingue-se de uma seqüência de vogais pelo fato de o ditongo ocorrer em uma única sílaba enquanto que na seqüência de vogais cada vogal ocorre em sílaba diferente. Observe 
ainda que em seqüências de vogais - como na palavra país - cada uma das vogais tem proeminência acentual constituindo o pico de sílaba. Nos ditongos apenas uma das vogais tem proeminência acentual e constituirá o pico da sílaba. A outra vogal do ditongo não pode ocupar um pico silábico - caso contrário esta vogal ocuparia uma sílaba distinta e teríamos uma seqüência de vogais. As vogais que não ocupam o pico silábico nos ditongos - por exemplo o $i$ de pais - são aquelas que denominamos glide. O termo glide refere-se portanto às vogais sem proeminência acentual nos ditongos.

Transcrevemos foneticamente os glides com os símbolos identificados anteriormente adotados para as vogais. Como generalização para o português fazemos uso dos símbolos [I ] e [U్ ] para caracterizar os glides nos ditongos. O diacrítico _indica que o segmento vocálico em questão é assilábico ou seja, um segmento sem proeminência acentual que faz parte de um ditongo. Em outras línguas podem encontrar-se ter outras vogais além de [I I ] e [Ũ] correspondendo ao glide. No inglês britânico temos por exemplo o segmento [ə] ] representando a parte sem proeminência acentual em ditongos - ou seja, [ə] ] representa o glide: [dəə઼] door "porta".

Temos então seqüências de vogais que ocorrem em sílabas distintas, como em país. Temos também seqüências de vogais que ocorrem na mesma sílaba e correspondem a um ditongo sendo que uma das vogais na seqüência representa um glide (e portanto não pode ter proeminência acentual). Podemos portanto ter ditongos do tipo (vogal-glide) ou (glide-vogal). Chamamos de ditongo decrescente aqueles em que temos uma seqüência de (vogal-glide) como em 'g[aI ]ta'. Em oposição chamamos de ditongo crescente aqueles em que temos uma seqüência de (glide-vogal) como em estac/Iñolnamento.

A seguir discutimos algumas propostas de análise do sistema vocálico do português brasileiro baseadas no sistema das Vogais cardeais. O objetivo central desta análise é ilustrar a aplicação do método discutido neste artigo. A primeira aplicação do método é aquela apresentada em CAGLIARI (1981) que caracteriza as vogais do dialeto paulista. A segunda análise é aquela proposta por SILVA 
(1994). Finalmente, apresenta-se uma análise que toma como referência a análise acústica das vogais do português apresentada por CALLOU et al. (1996).

\section{A APLICAÇÃO DO MÉTODO DAS VOGAIS CARDEAIS}

\subsection{A proposta de CAGLIARI (1981)}

Cagliari descreve o método das Vogais cardeais e apresenta uma lista de palavras que exemplificam algumas das vogais típicas do dialeto paulista (CAGLIARI, 1981:50). Juntamente a estas vogais ele apresenta o diagrama vocálico em que tais segmentos são identificados. Este diagrama com os exemplos apresentados pelo autor são ilustrados abaixo.

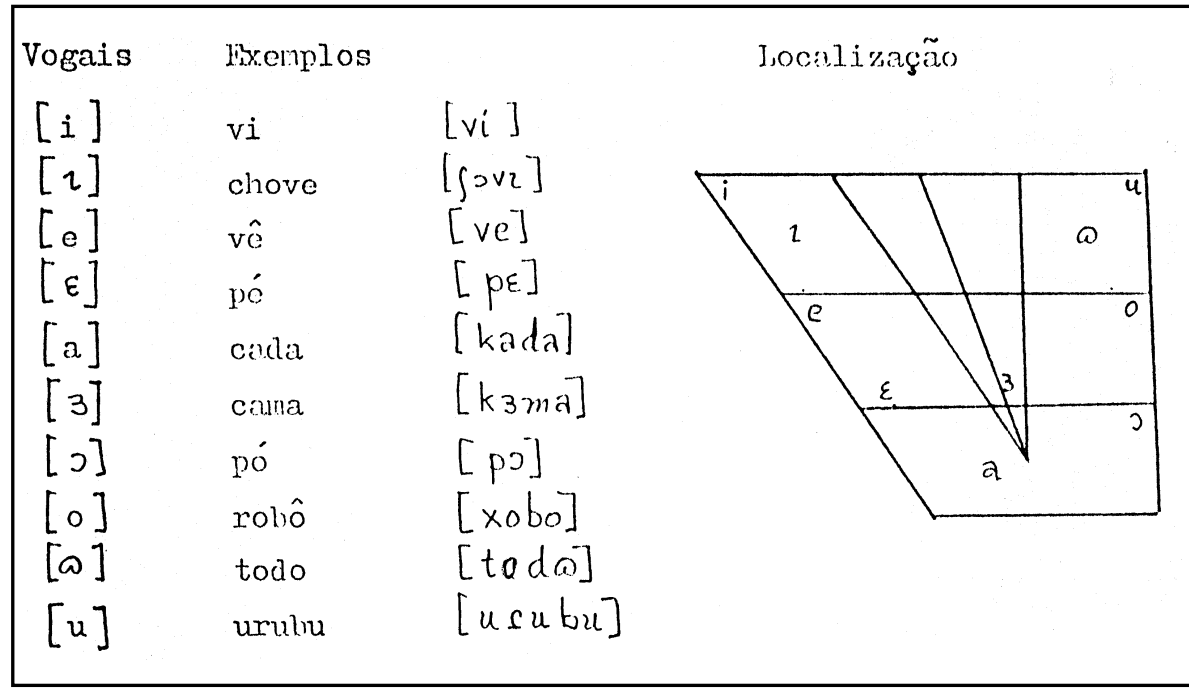

FIGURA 7 - Diagrama vocálico com a localização das vogais mais comuns do português brasileiro juntamente com exemplos.

FONTE - CAGLIARI, 1981. p.50. 


\subsection{A proposta de SILVA (1994)}

Os segmentos vocálicos descritos por SILVA (1994) ocorrem tipicamente no português de Belo Horizonte. A localização desses segmentos na área vocálica é apresentada abaixo. Ilustram-se os segmentos caracterizando-os como tônicos e átonos. Os segmentos átonos podem ser pretônico, postônico medial ou postônico final.

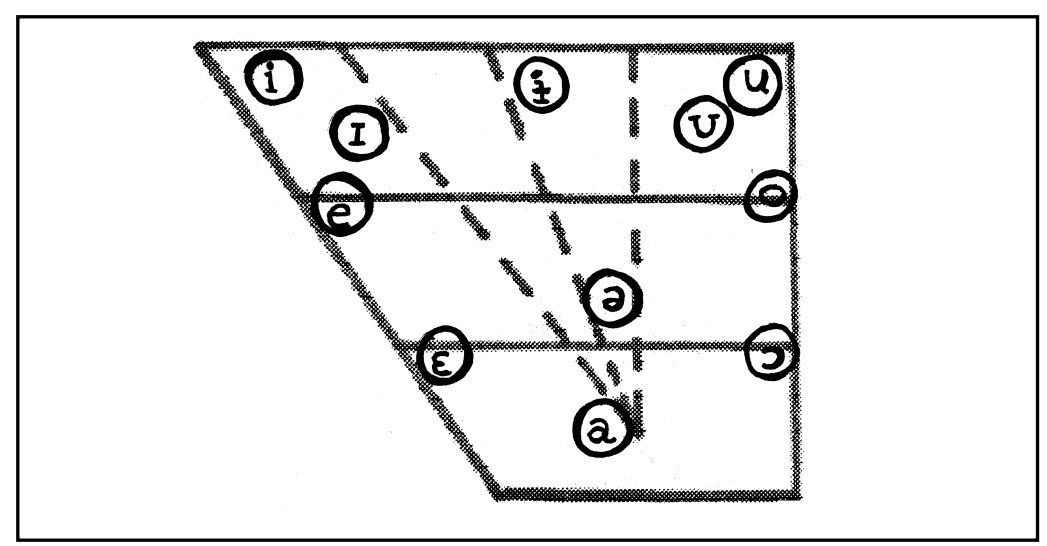

FIGURA 8 - Diagrama vocálico com a localização ds vogais identificadas para o dialeto de Belo Horizonte

FONTE - SILVA, 1994.

Exemplos que ilustram cada um dos segmentos identificados acima são agrupados a seguir. ${ }^{5}$ As áreas sombreadas indicam que tal segmento não ocorre para tal posição acentual. Uma mesma palavra que ocorre duas vezes associada a símbolos fonéticos diferentes indica variação dialetal. 


\section{QUADRO 2}

Exemplos de palavras com as vogais identificadas na FIG. 8

\begin{tabular}{l|l|l|l|l}
\hline & pretônico & tônico & postônico medial & postônico final \\
\hline$\dot{i}$ & pirata & vi & álibi & mole \\
$e$ & pedaço & lê & número, hipótese & mole \\
$\varepsilon$ & pedrinha & fé & hipótese & - \\
a & parada & pá & sílaba & cara \\
o & molíssimo & pó & pérola & - \\
o & coreto & alô & pérola & pato \\
$u$ & buraco & anu & cédula & pato \\
I & pirata & - & álibi, hipótese & mole \\
$ə$ & parada & - & sílaba & cara \\
$\dot{\text { a }}$ & - & - & número & - \\
$u$ & buraco & - & pérola, cédula & pato \\
\hline
\end{tabular}

\subsection{A proposta de CALLOU et al. (1996)}

CALLOU et al. (1996) apresentam uma análise do vocalismo do português do Brasil. Tal análise explicita os parâmetros acústicos das vogais tônicas e átonas em cinco dialetos do português brasileiro. ${ }^{6}$ Tal análise considera dados de fala espontânea de falantes de três faixas etárias. Comparam-se ainda os segmentos vocálicos do português brasileiro e europeu (ver ANEXO).

Esta análise compara as médias gerais de F1 e F2 obtidas através do cálculo dos valores médios das cinco capitais com os dados do português europeu (MARTINS, 1973) e também com as médias estabelecidas por CATFORD (1988) para as vogais cardeais. $\mathrm{Na}$ caracterização acústica os valores do primeiro formante F1 estão relacionados ao grau de abertura (ou altura do segmento). Já para o segundo formante os valores de F2 caracterizam o grau de anteriorização/posteriorização. Apresentamos a seguir o diagrama das Vogais Cardeais identificando as sete vogais tônicas do português

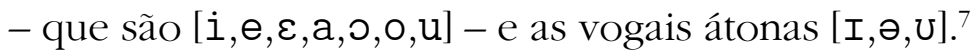




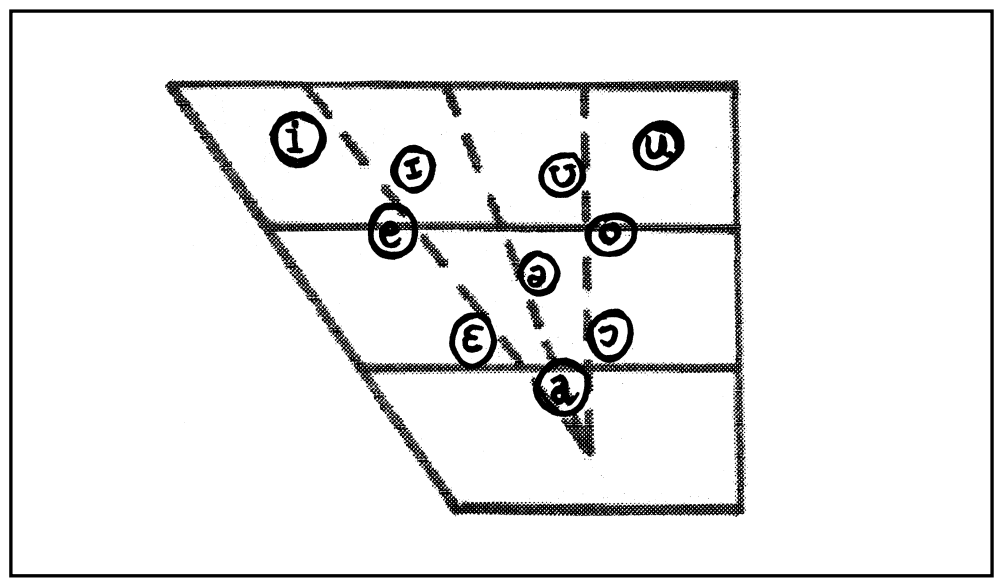

FIGURA 9 - Identificação das vogais orais do português brasileiro seguindo a análise de CALLOU et al. (1996: 40)

Comparando as vogais do português brasileiro com as vogais cardeais, CALLOU et al. (1996:32) observam que:

1. As vogais baixas $/ \varepsilon, a /$ são consideravelmente mais altas.

2. As vogais altas $/ i, u /$ são mais baixas.

Como generalização observam ainda que todo o sistema do português brasileiro tende a ser centralizado em relação às vogais cardeais primárias. Em outras palavras o sistema vocálico tende a ser menos polarizado.

\section{CONCLUSÃO}

Há consenso entre os lingüistas quanto às vogais orais tônicas do português brasileiro: ${ }^{8}[i, e, \varepsilon, a, \supset, o, u]$. Os lingüístas são também unânimes em discutir a relação entre a distribuição dos segmentos vocálicos em relação à tonicidade no português. Há portanto uma relação direta entre a tonicidade e a distribuição das vogais. As análises variam sobretudo quanto ao número de segmentos vocálicos átonos que ocorrem em um dado sistema. Na verdade conhecemos ainda pouco do sistema vocálico do português brasileiro. Precisamos de 
descrições esclarecedoras que sejam bem delineadas metodologicamente. Devemos estar atentos a aspectos lingüísticos e extralingüísticos.

Como parâmetro extralingüístico aponto a delimitação do córpus em termos de informantes de faixas etárias e graus de instrução variados. Deve-se ainda levar em conta fatores como sexo. Falantes devem ser de uma determinada região geográfica cujos limites sejam claramente definidos.

Como parâmetros lingüísticos é importante buscar uma descrição acurada do ponto de vista articulatório e auditivo. Deve-se também tentar buscar os correlatos acústicos para os segmentos a serem descritos. Creio ser mais adequado localizar as vogais cardeais no diagrama tridimensional que expressa os parâmetros articulatórios: (alto $\leftrightarrow$ baixo); (anterior $\leftrightarrow$ posterior) e (arredondado $\leftrightarrow$ não-arredondado).

A descrição de sistemas vocálicos de vários dialetos certamente nos fornecerá mais dados para os estudos dialetológicos. Poderemos identificar ainda traços essenciais à caracterização dos segmentos vocálicos do português. Listo abaixo alguns fatores estruturais que acredito serem pertinentes na descrição das vogais:

1. Tonicidade (pretônica, tônica, postônica medial, postônica final).

2. Estrutura silábica investigando alongamento (já atestei casos de tosse e torce serem homófonas!).

3. Morfologia (sufixos como -inh, -zinh, -issim, -mente requerem sempre vogal aberta pretônica. Há outros sufixos? Quais?).

4. Harmonia (em alguns dialetos a vogal pretônica pode ser aberta se a vogal tônica for também aberta ou nasal: colega, remoto, setembro, noventa, etc.).

5. Posição na palavra em relação ao acento (há certamente diferença em casos em que não temos epêntese ( $a f t a, \operatorname{dog} m a$ ), para os casos em que a vogal epentética ocorre (affilta, dogiilma,). Há também casos de cancelamento de vogal como xícra, abóbra que afetam a vogal tônica (sobretudo quanto à duração). 
6. Relação com o padrão rítmico (o acento secundário em cafezinho e a falta (opcional) de acento secundário em cafezal podem alterar a qualidade vocálica?).

Estes são alguns pontos que levanto apenas como questionamento. Há ainda muito trabalho a ser feito. Quanto mais soubermos sobre as especificidades dialetais melhores conseguiremos descrever o sistema fonológico sincrônio do português. Além dos esclarecimentos teóricos, teremos a contribuição indireta aos estudos de aquisição da linguagem, aprendizado/ensino de língua materna e estrangeira, patologia da fala, variação e mudança lingüística e outros.

\section{NOTAS}

${ }^{1}$ Uma versão preliminar deste texto foi escrita com o objetivo de ser apresentada no corpo do livro intitulado Fonética e fonologia do português; roteiro de estudos e guia de exercícios (1999), Contexto. Contudo, aceitando opinião de leitores da versão preliminar de tal livro segui a sugestão de caracterizar as vogais com parâmetros articulatórios. Os argumentos seriam que em descrições de cunho fonêmico a caracterização das vogais segue parâmetros articulatórios e também de que deveria ser dada continuidade à caracterização articulatória apresentada para as consoantes. Contudo, proponho agora este trabalho com objetivo de divulgar o Método das vogais cardeais por acreditar que tal técnica permite uma descrição mais acurada e teoricamente mais elegante para descrever os segmentos vocálicos.

${ }^{2}$ Um segmento vocálico é um som articulado com a passagem livre da corrente de ar pelo trato vocal de maneira que não haja obstrução ou fricção da passagem da corrente de ar. Os segmentos vocálicos são produzidos a partir das diferentes configurações assumidas pela língua na cavidade bucal.

${ }^{3}$ Agradecemos à Associação Internacional de Fonética por gentilmente autorizar a reprodução deste quadro.

${ }^{4}$ Em descrição detalhada dos ditongos em pai s e pau s observamos que o segmento [a] apresenta características articulatórias diferentes em cada caso. Ou seja, o [a] em pai s e pau s é diferente e a diferença está relacionada ao fato do glide seguinte ser anterior ( $\mathrm{p} \boldsymbol{a i} \mathrm{s}$ ) ou posterior ( $\mathrm{p} \boldsymbol{a \boldsymbol { u }}$ ). Por razões didáticas assumimos no diagrama da figura 6 que o segmento [a] nos ditongos é idêntico em pai s e pau s. 
${ }^{5}$ Vale ressaltar que entre falantes do português de Belo Horizonte palavras como levar/lavar e levo/lavo podem ser homófonas. Encontram-se problemas de interpretação semântica em casos como Deixa que eu levo/lavo ou Eu vou 'evar/lavar em que vogais tônicas ou pretônicas podem apresentar a mesma qualidade vocálica.

${ }^{6}$ Dados do NURC: Norma Urbana Culta em Porto Alegre, São Paulo, Rio de Janeiro, Salvador e Recife.

${ }^{7}$ Excluímos a análise do português europeu por termos como objetivo a caracterização de segmentos vocálicos do português do Brasil. Apresentam-se ao final do artigo os gráficos de correlação de F1 e F2 de CALLOU et al (1996) para as vogais tônicas e átonas. O diagrama identifica as vogais do português a partir dos dados apresentados para a análise experimental. Adotamos os símbolos [I,ə,U] para as vogais caracterizadas como [i,a,u] átonos em CALLOU et al (1996:30). Nosso objetivo é distingui-las das vogais tônicas uma vez que tônicas e átonas diferem acusticamente conforme explicitado por CALLOU et al (1996).

${ }^{8}$ Todos os dialetos do Português Brasileiro apresentam estas vogais, embora possa ocorrer variação com as vogais médias e/ $\varepsilon$ e o/ o. Temos por exemplo pronúncias concorrentes para palavras como $\mathrm{t}[\mathrm{e}] \mathrm{xtil} / \mathrm{t}[\varepsilon] \mathrm{xtil}$ ou para $\mathrm{p}[\mathrm{o}] \mathrm{ça} / \mathrm{p}[\mathrm{o}]$ ça. Assumo que tais casos refletem variacões individuais dos falantes.

\section{REFERÊNCIAS BIBLIOGRÁFICAS}

ABERCROMBIE, D. Elements of General Phonetics. Edinburgh: Edinburgh University Press, 1967.

CAGLIARI, L. Elementos de fonética do português brasileiro. Campinas: UNICAMP, 1981 (Tese de Livre Docência).

CALLOU, D., MORAES J., LEITE, Y. O vocalismo do português do Brasil. Letras de Hoje, n. 104, v.31, PUCRS, Porto Alegre, 1996.

CATFORD, J. A practical introduction to Phonetics. Oxford: Claredon Press, 1988.

IPA: The Principles of the International Phonetic Association. International Phonetic Association. London: University College, 1982.

. O alfabeto internacional de fonética. Versão autorizada em português em SILVA (1999: 41), 1996.

JONES, D. The Pronunciation of English. 4. ed. Cambridge: Cambridge University Press, 1969. (1. ed. 1909)

. An Outline of English Phonetics. Cambridge: Cambridge University Press, 1980. (1. ed. 1918) 
LADEFOGED, P., MADDIESON, I. The Sounds of the Worlds Languages. Oxford: Blackwell, 1996.

LAVER, J. Principles of Phonetics. Cambridge: Cambridge University Press, 1994. MARTINS, M. R. Delgado. Análise acústica das vogais orais tônicas em português. Boletim de Filologia, v.XXII, n.3-4, p.303-314, 1973.

ROCA, I., JOHNSON, W. A Course in Phonology. Oxford: Blackwell, 1999.

SILVA, Thaïs Cristófaro. Descriçãofonética e análise de alguns processos fonológicos da lingua krenak. Belo Horizonte: Faculdade de Letras da UFMG, 1986. (Dissertação de Mestrado em Lingüística).

. Fonética e Fonologia do português: roteiro de estudos e guia de exercícios. São Paulo: Contexto, 1999. 


\section{ANEXO}

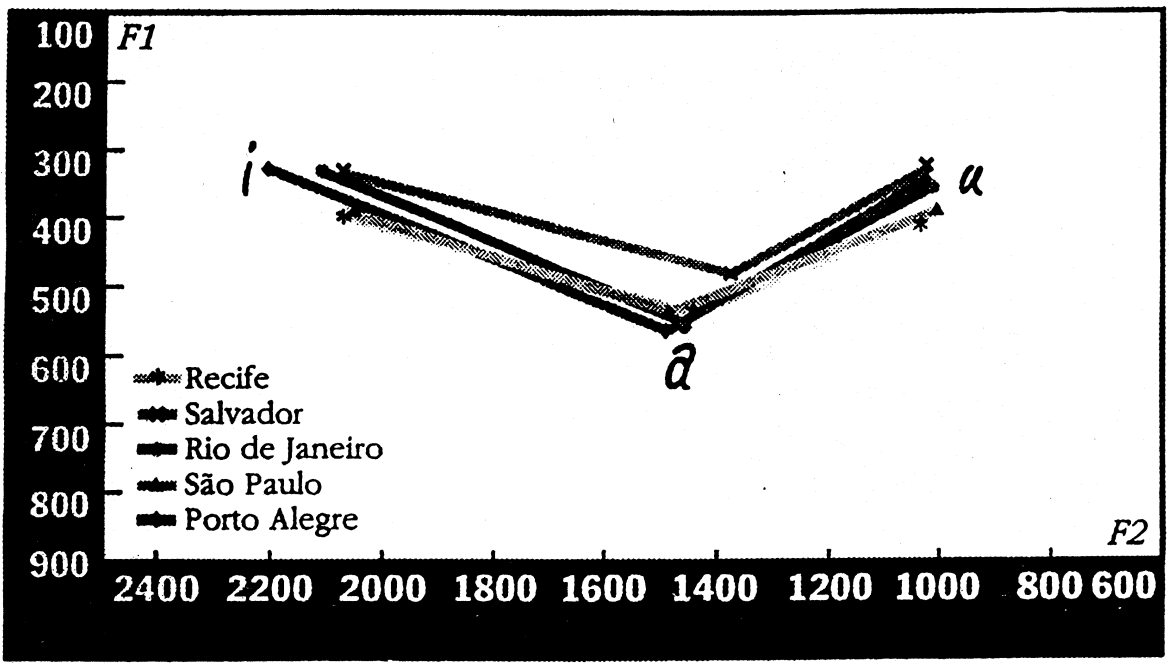

FIGURA 3 - Vogais postônicas - Configuração por região.

FONTE - CALLOU et al. (1996:38).

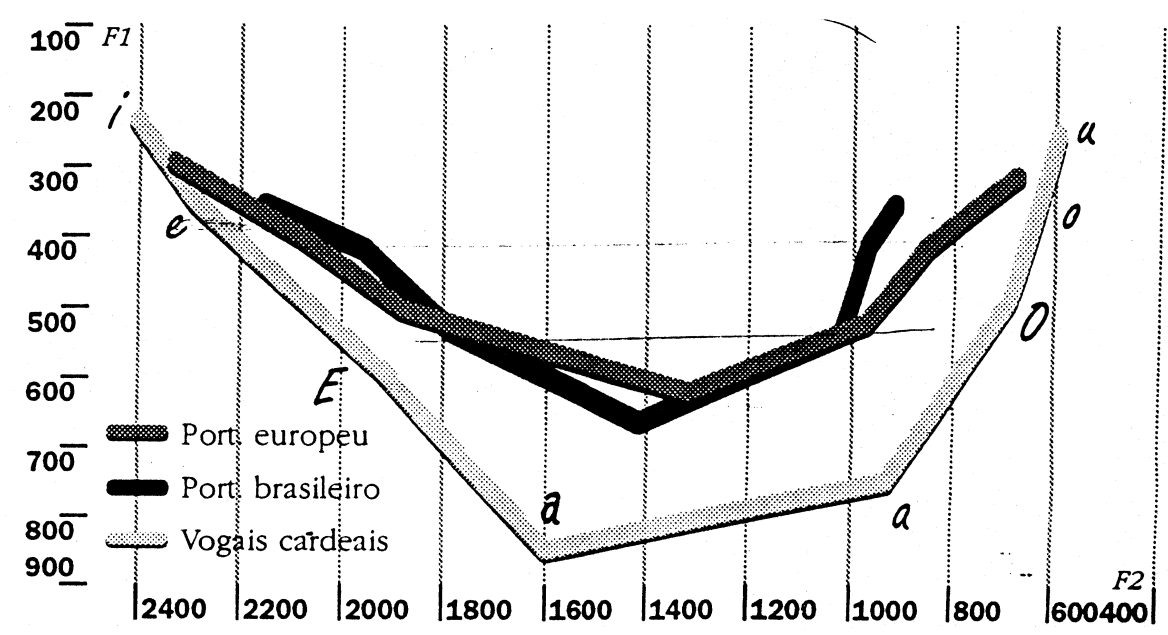

FIGURA 5 - Português europeu, português brasileiro e vogais cardeais. FONTE - CALLOU et al. (1996:40). 